\title{
Apoptosis-Associated Speck-Like Protein Containing A CARD
}

National Cancer Institute

\section{Source}

National Cancer Institute. Apoptosis-Associated Speck-Like Protein Containing A CARD. NCI Thesaurus. Code C93109.

Apoptosis-associated speck-like protein containing a CARD (195 aa, $22 \mathrm{kDa}$ ) is encoded by the human PYCARD gene. This protein plays a role in promotion of caspase activation and the initiation of apoptosis. 